\title{
PREFACE
}

When Theodosius Dobzhansky's Genetics of the Evolutionary Process (the final edition of several that were initially titled Genetics and the Origin of Species) appeared in 1970, one reviewer confessed to a sigh of relief. At the outset, he had been concerned that Dobzhansky, in attempting to make a final revision at an advanced age, would produce a parody of the text that had been the cornerstone of the Modern Synthesis. His worries, the reviewer learned, had been baseless. Perhaps they can now be reawakened by my attempt to review fifty years of genetic load; I can only hope that the same reviewer's fears will prove baseless once more.

Although I am a population geneticist, my approach to the study of populations has not been traditional. I have never run a computer simulation. I have not studied allozyme variation extensively, nor, outside the classroom, have I ever calculated a genetic distance. I have never indulged in mathematics much higher than high school algebra.

The nontraditional nature of my research is explained, I think, by an eleven-year sojourn at Cold Spring Harbor, New York, that began as I left Dobzhansky's laboratory at Columbia University. At weekly staff meetings I had to report on my research to an audience that included Milislav Demerec (director of both the Biological Laboratory at Cold Spring Harbor and the Department of Genetics of the Carnegie Institution of Washington), A. D. Hershey, Barbara McClintock, and Evelyn 
Witkin. None of these persons was a population geneticist, but each had an intense interest in science, and each possessed a tremendous intellect. My task was to state my current research problem clearly and to describe the procedures by means of which I intended to solve it. If I succeeded in my report, every comment from the audience-no matter how casually made-was a valuable one requiring at times hours of thought.

One issue regarding the use of Hardy-Weinberg equilibria (an issue that was subsequently addressed by four authors in correspondence to Evolution at the time and that has been resurrected by still another within the 1980s) was summarized by Hershey as follows: "If you know where you are but you do not know where you started, then you cannot say how you got there." True! One can only guess at the most likely path.

Summers and the annual Cold Spring Harbor symposia brought still larger audiences to be addressed; among the regular visitors were Max Delbrück, S. E. Luria, Guido Pontecorvo, Leo Szilard, Ernst Caspari, and (then a young graduate student) J. D. Watson. For these personsmost of whom (with the notable exception of Barbara McClintock) were phage and microbial geneticists - research problems had to be precise if they were to be worthwhile, and laboratory procedures aimed at solving them had to involve the fewest possible assumptions. I recall with some pride a local staff member telling me one June afternoon that mine was the only symposium paper of the day that dealt with a clearly defined problem and involved reasoning and research procedures that he could understand.

A second memory is of a morning in conversation with Delbrück, at his insistence; he was preparing himself for the task of teaching general biology at Cal Tech-a task for which he had volunteered. Our talk got around to the fate of a single mutant gene in a large diploid population. Knowing that each pair of parents must be replaced by two offspring, I said that the probability of losing the gene from the population was $\frac{1}{2} \times \frac{1}{2}$, or $\frac{1}{4}$. Delbrück was surprised at this; he cited the Poisson distribution and claimed that the probability of loss would be 0.37 . He would not let me concede error, however, and move on to another topic. We were both correct, he explained, and therefore there must be an explanation for our different answers. Shortly, the explanation occurred to him: my calculation had removed variation in num- 
bers of progeny per pair of parents. Subsequently, I noticed that both solutions to this problem had been included among the chapter-end exercises of one widely used genetics textbook.

The environment at Cold Spring Harbor was not oné that encouraged an extensive use of quantitative genetics; had I gone (as I might have) to North Carolina State University in the mid-1950s, I would have joined S. G. Stephens, H. F. Robinson, R. E. Comstock, and C. C. Cockerham, and my subsequent research would undoubtedly have been profoundly influenced by these good friends.

There were no ecologists at Cold Spring Harbor; hence, I had no opportunity to take part in the creation of a population biology as did, for example, R. C. Lewontin, Robert MacArthur, Richard Levins, and E. O. Wilson (four Young Turks in 1968, when Lewontin edited the symposium volume Population Biology and Evolution) through their collaboration with one another and with other university colleagues. My contact with ecologists was postponed until my arrival at Cornell University, where Simon Levin, Richard Root, and William Brown became welcome colleagues. My participation in the symposium that Lewontin arranged at Syracuse University in 1967 was entirely accidental; I had sent him a manuscript requesting criticism and comments. His response was an invitation to present the material at Syracuse, hence my participation in, or at least my presence at, the creation of population biology.

Because all research at the Biological Laboratory during the $1950 \mathrm{~s}$ was supported by "soft" money, the pace was not the leisurely one generally associated with university departments. When asked how the staff at the Biological Laboratory could accomplish so much, Vernon Bryson, a colleague, responded that when next year's salary depends upon this year's accomplishments, one works harder. This pace discouraged the use of students to perform what was essentially contract research. During special experiments called "big pushes," half the laboratory technicians would work the usual 8 A.M. -5 P.M. shift, and the remaining half would work from noon until the day's work ended near 10 P.M. During such times my colleague J. C. King and I would work from 8 A.M. until near midnight. A two-day holiday would be declared at the termination of such an experiment; New York State's Fair Employment Practices Act had not yet become law.

The account given here of the influence those eleven years at Cold 
Spring Harbor had on my research efforts may explain my unconventionality, but it does not excuse it, if, in fact, it needs excusing. In retrospect, I feel that each phase of my research has more or less set the stage for the next one. There has been a continuity that, in my view, has conferred an overall pattern on my work; this pattern includes a gradual change in my point of view-a change based on what I consider to be a series of rational judgments. I can imagine, in contrast, having spent my life studying empirical relationships between genetic markers and some physiological trait in natural populations in which existing complexities would have precluded predictions. After a lapse of several decades, a younger worker might repeat my study and find that the relationships I had observed no longer held. At that time, I would probably publish a joint paper with the younger person, dealing with and speculating on the reversal of a longtime correlation. To what purpose? This is precisely the type of study that would have palled at Cold Spring Harbor-one that my then colleagues would have either ignored or vigorously criticized. I greatly appreciate the guiding influence that those marginally interested parties had on my early scientific development, largely by example but also by their insightful comments on my research.

In concluding these remarks, I wish to thank the Alexander von Humboldt-Stiftung for the Senior U.S. Scientist Award (1986 and 1987), which made writing this book possible. Professor Diether Sperlich, my host at the University of Tübingen, and his colleagues provided a most gracious and stimulating environment within which to work; I thank them for their many kindnesses. Several colleagues read and commented encouragingly on the penultimate draft of this manuscript: John Beatty of the University of Minnesota, Robert May of Oxford University, Ernst Mayr of Harvard University, and Will Provine of Cornell University. I owe them all many thanks, including the one who observed that this "is by no means a balanced treatment by a disinterested observer." I concede that he is quite right: this is an account of $m y$ odyssey in which I emphasize the floes, whirlpools, reefs, and shoals that threatened me during my voyage.

BRUCE WALLACE

Blacksburg, Virginia 


\section{FIFTY YEARS OF}

GENETIC LOAD 
